\title{
A New Nucleoside Derivative, AJP117510, as an Inhibitor of Integrin $\alpha_{2} \beta_{1}$-Collagen Binding
}

\author{
Seiichi Sato $^{\dagger}$, Fumie Futaki, Naoyuki Fukuchi, Kenichi Kaida ${ }^{\dagger \dagger}$, Masako Hiraga ${ }^{\dagger \dagger}$, \\ Seikichi Kobaru, Takashi Tsuji ${ }^{\dagger}$
}

Received: March 6, 2006 / Accepted: April 7, 2006

(C) Japan Antibiotics Research Association

\begin{abstract}
A new nucleoside derivative, AJP117510 (1) was isolated from unidentified fungus AJ117510. The structure of 1 was elucidated by spectroscopic analyses. Nucleoside 1 inhibited the binding of integrin $\alpha_{2} \beta_{1}$ to collagen in a dose dependent manner with an $\mathrm{IC}_{50}$ value of $5.9 \mu \mathrm{M}$.
\end{abstract}

Keywords AJP117510, integrin $\alpha_{2} \beta_{1}$, collagen, inhibitor, nucleoside

The platelet membrane glycoprotein integrin $\alpha_{2} \beta_{1}$ is an important collagen receptor in hemostasis [1]. Platelet adhesion to subendothelial collagen that is exposed upon damage of the vessel wall is one of the initiating steps in thrombus formation [2]. In our search for novel antiplatelet agents based on the interaction between integrin $\alpha_{2} \beta_{1}$ and extracellular matrix collagen, a novel nucleoside derivative,

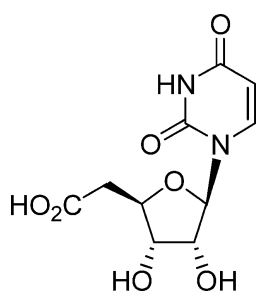

Fig. 1 Structure of AJP117510 (1).
AJP117510 (1) was isolated from unidentified fungus AJ117510 (Fig. 1). 1 inhibited the binding of integrin $\alpha_{2} \beta_{1}$ to collagen in a dose dependent manner in vitro. We describe isolation, structure elucidation, and inhibitory activity of integrin $\alpha_{2} \beta_{1}$-collagen binding of $\mathbf{1}$.

Unidentified fungus AJ117510 was isolated from fruiting body of unidentified discomycete collected at Yamanashi Prefecture, Japan. A slant culture of strain AJ117510 was maintained on an agar slant. A 28-day culture at $25^{\circ} \mathrm{C}$ of the agar slant was transferred into twenty of Roux flasks containing $100 \mathrm{ml}$ of a producing medium composed of glucose $0.2 \%$, fructose $0.5 \%$, sucrose $0.8 \%$, NZ-Case (Humco) $0.2 \%, \mathrm{MgSO}_{4} \cdot 7 \mathrm{H}_{2} \mathrm{O} \quad 0.05 \%, \quad \mathrm{KCl} \quad 0.05 \%$, $\mathrm{ZnSO}_{4} \cdot 7 \mathrm{H}_{2} \mathrm{O} 0.05 \%$, and $\mathrm{KH}_{2} \mathrm{PO}_{4} 0.1 \%$ (pH 6.0). The fermentation was carried out at $25^{\circ} \mathrm{C}$ for 14 days. The mycelium of AJ117510 was extracted with acetone (4 liters) at room temperature. The acetone extract was concentrated in vacuo to give an aqueous suspension. The concentrate was partitioned between $n$ - $\mathrm{BuOH}$ and $\mathrm{H}_{2} \mathrm{O}$. The aqueous layer was dried in vacuo. The residue was applied to a Dowex $1 \mathrm{X} 8\left(\mathrm{AcO}^{-}\right)$column $(3.0$ i.d. $\times 16 \mathrm{~cm})$. After washing with deionized water, the active compound was eluted with $5 \sim 10 \%$ aqueous acetic acid. The active fraction was subjected to a Dowex 50WX4 $\left(\mathrm{H}^{+}\right)$column $(2.2$ i.d. $\times 20 \mathrm{~cm})$, and eluted with deionized water. Further purification was performed by DEAE-TOYOPEARLPAK $650 \mathrm{~S}\left(\mathrm{AcO}^{-}\right)(2.2$ i.d. $\times 20 \mathrm{~cm})$ with a linear gradient from 0 to $10 \%$ aqueous acetic acid at a flow rate of $4.0 \mathrm{ml} /$ minute to give $\mathbf{1}(510 \mathrm{mg})$ (Scheme 1).
S. Sato (Corresponding author), F. Futaki, N. Fukuchi, K. Kaida, M. Hiraga, S. Kobaru, T. Tsuji: Pharmaceutical Research Laboratories, Ajinomoto Co., Inc., 1-1 Suzuki-cho, Kawasaki 210-8681, Japan, E-mail: seiichi_sato@ajinomoto.com

\footnotetext{
${ }^{\dagger}$ Present address: AminoScience Laboratories

${ }^{\dagger \dagger}$ Present address: Institute of Life Sciences
} 
The physico-chemical properties of $\mathbf{1}$ are shown in Table 1. The UV spectrum of $\mathbf{1}$ showed absorption maximum at $261 \mathrm{~nm}$. The molecular formula of $\mathbf{1}$ was established to be $\mathrm{C}_{10} \mathrm{H}_{12} \mathrm{O}_{7} \mathrm{~N}_{2}$ by HR-FAB MS. 1 was negative to ninhydrin and $\mathrm{FeCl}_{3}$ reagent. The ${ }^{1} \mathrm{H}(400 \mathrm{MHz})$ and ${ }^{13} \mathrm{C} \mathrm{NMR}$ (100 MHz) spectral data of $\mathbf{1}$ are shown in Table 2.

The ${ }^{1} \mathrm{H}$ NMR spectrum showed a methylene proton $(\delta$ 2.65 and 2.81), three carbinyl protons ( $\delta 4.02,4.23$, and $4.26)$, an anomeric proton ( $\delta 5.70)$, and two aromatic protons. When considered together, the UV spectrum and the ${ }^{1} \mathrm{H}$ NMR signals in the aromatic region indicated the presence of uracil moiety. These results suggested that $\mathbf{1}$ was nucleoside derivative related to uridine. The difference between 1 and uridine was that the chemical shift values of the protons at C-5' methylene of $\mathbf{1}$ were observed at higher field ( $\delta 2.65$ and 2.81) than those of uridine ( $\delta 3.81$ and 3.92). The large $J$ value between the geminal protons

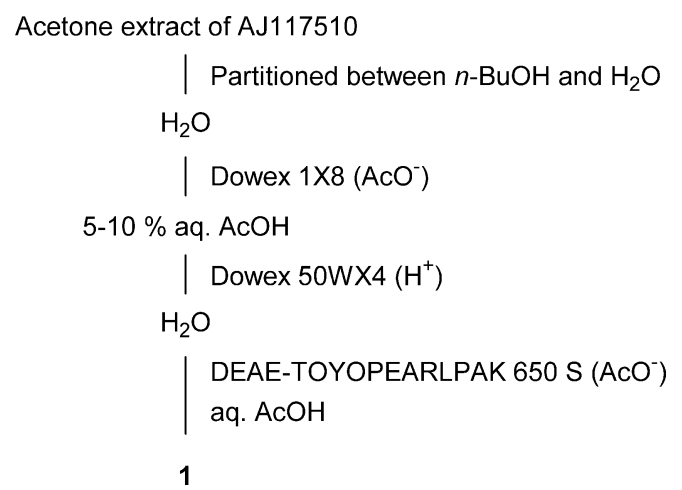

Scheme 1 Isolation procedure for 1.
( $16.4 \mathrm{~Hz}$ ) indicated that the $\mathrm{C}-5^{\prime}$ methylene was in the $\alpha$ position of the carbonyl group. ${ }^{13} \mathrm{C}$ NMR spectrum supported a presence of uracil moiety $(\delta$ 104.6, 144.3, 153.7, and 168.4), furanose moiety ( $\delta 39.7,74.5,75.1$, 82.0, and 92.5), and carboxylic acid ( $\delta$ 176.9). Connectivities from $\mathrm{C}-1^{\prime}$ to $\mathrm{C}-5^{\prime}$, and C-5 to C-6 were established by the ${ }^{1} \mathrm{H}-{ }^{1} \mathrm{H}$ COSY spectrum. Furthermore, the HMBC correlation data connected $\mathrm{C}-1^{\prime}$ and $\mathrm{N}-1$, and $\mathrm{C}-5^{\prime}$ and carboxylic acid moiety. Thus, the structure of $\mathbf{1}$ was determined as carboxylic acid analogue in place of the hydroxyl group at $\mathrm{C}-5^{\prime}$ of uridine (Figure 2). The $J$ values in the sugar moiety of $\mathbf{1}$ were good agreement with those of uridine (Table 3). The elucidated structure of $\mathbf{1}$ is similar to the nucleoside skeleton of polyoxins [3]. Biosynthesis of similar 5'-elongated nucleoside polyoxins have been reported previously [4]. Analogously, 1 would be biosynthsized via 5'-aldehyde of uridine and the absolute configuration of $\mathbf{1}$ was deduced to be same as uridine.

Effect of 1 on the interaction of integrin $\alpha_{2} \beta_{1}$ and

Table 1 Physico-chemical properties of 1

\begin{tabular}{ll}
\hline Appearance & colorless needles \\
Melting point & $202 \sim 205^{\circ} \mathrm{C}$ \\
Molecular formula & $\mathrm{C}_{10} \mathrm{H}_{12} \mathrm{O}_{7} \mathrm{~N}_{2}$ \\
HR FAB-MS $(\mathrm{m} / \mathrm{z})$ & \\
Found $(\mathrm{M}-\mathrm{H})^{-}$ & 271.0551 \\
Calcd & 271.0566 \\
UV $\lambda_{\max }^{\mathrm{H}_{2} \mathrm{O}} \mathrm{nm}(\varepsilon)$ & $261(19100)$ \\
{$[\alpha]_{D}^{23}$} & $+30.8^{\circ}\left(\mathrm{c} 0.5, \mathrm{H}_{2} \mathrm{O}\right)$ \\
\hline
\end{tabular}

Table $2{ }^{1} \mathrm{H}$ and ${ }^{13} \mathrm{C}$ NMR spectral data of $\mathbf{1}$ recorded in $\mathrm{D}_{2} \mathrm{O}$

\begin{tabular}{|c|c|c|c|}
\hline \multirow{2}{*}{ Position } & \multicolumn{2}{|l|}{1} & \multirow{2}{*}{$\begin{array}{l}\text { Uridine } \\
\qquad{ }^{1} \mathrm{H}\end{array}$} \\
\hline & ${ }^{1} \mathrm{H}$ & ${ }^{13} \mathrm{C}$ & \\
\hline 2 & - & 153.7 & - \\
\hline 4 & - & 168.4 & - \\
\hline 5 & $5.75\left(d, J=8.0^{a}\right)$ & 104.6 & $5.90(d, J=8.4)$ \\
\hline 6 & $7.52(d, J=8.0)$ & 144.3 & 7.88 (d. $J=8.4)$ \\
\hline $1^{\prime}$ & $5.70(d, J=4.4)$ & 92.5 & $5.92(d, J=4.8)$ \\
\hline $2^{\prime}$ & $4.26(\mathrm{dd}, J=4.4,5.6)$ & 75.1 & $4.36(\mathrm{dd}, J=4.8,5.2)$ \\
\hline $3^{\prime}$ & $4.02(t, J=5.6)$ & 74.5 & $4.23(\mathrm{dd}, J=5.2,5.6)$ \\
\hline $4^{\prime}$ & 4.23 (ddd, J=4.4, 5.6, 8.8) & 82.0 & 4.14 (ddd, $J=2.8,4.4,5.6$ ) \\
\hline $5^{\prime} \mathrm{a}$ & $2.65(\mathrm{dd}, J=8.8,16.4)$ & 39.7 & $3.92(\mathrm{dd}, J=2.8,12.8)$ \\
\hline $5^{\prime} b$ & $2.81(\mathrm{dd}, J=4.4,16.4)$ & & $3.81(\mathrm{dd}, J=4.4,12.8)$ \\
\hline $6^{\prime}$ & - & 176.9 & - \\
\hline
\end{tabular}

${ }^{a}$ Multiplicity, $\mathrm{J}$ in $\mathrm{Hz}$. 


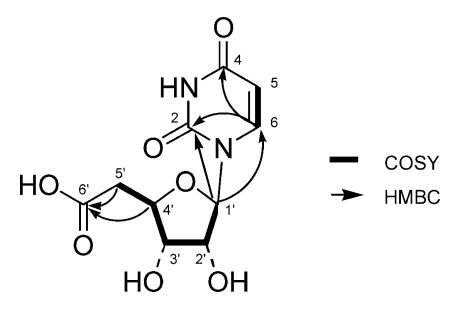

Fig. $2{ }^{1} \mathrm{H}-{ }^{1} \mathrm{H}$ COSY and selected $\mathrm{HMBC}$ correlations of 1.

Table $3{ }^{1} \mathrm{H}-{ }^{1} \mathrm{H}$ coupling constants of sugar moiety of $\mathbf{1}$ and uridine

\begin{tabular}{cccc}
\hline & $J_{1^{\prime}-2^{\prime}}$ & $J_{2^{\prime}-3^{\prime}}$ & $J_{3^{\prime}-4^{\prime}}$ \\
\hline $\mathbf{1}$ & 4.4 & 5.6 & 5.6 \\
Uridine & 4.8 & 5.2 & 5.6 \\
\hline
\end{tabular}

immobilized collagen was evaluated by using dissociationenhanced lanthanide fluorescence immunoassay (DELFIA) method [5]. 1 and europium (Eu)-labeled integrin $\alpha_{2} \beta_{1}$ in assay buffer (Wallac Inc.) including $2 \mathrm{mM} \mathrm{MgCl}_{2}$ were applied to each well of a collagen-coated microtiterplate. The plate was incubated for 2 hours. After washing the plate, enhancement solution (Wallac Inc.) was added. Time-resolved fluorometry of Eu was used to measure the level of the binding. The Eu signal was detected with excitation at $340 \mathrm{~nm}$ and emission at $615 \mathrm{~nm}$. Nucleoside 1 inhibited the binding of integrin $\alpha_{2} \beta_{1}$ to collagen in a dose dependent manner with an $\mathrm{IC}_{50}$ value of $5.9 \mu \mathrm{M}$. Uridine exhibited no activity at a dose of $120 \mu \mathrm{M}$ in this assay.

No cytotoxicity against P388 murine leukemia cells was observed at a dose of $294 \mu \mathrm{M}$. The absolute configuration and synthesis of its analogues are under investigation.

Acknowledgement We wish to thank Dr. Hideyuki Nagao (University of Tsukuba) for providing the strain AJ117510. We are also grateful to Reiko Yuji, Naoko Shimba, and Mina Nakamura for measurement of mass and NMR spectra.

\section{References}

1. Knight CG, Morton LF, Onley DJ, Peachey AR, Messent AJ, Smethurst PA, Tuckwell DS, Farndale RW, Barnes MJ. Identification in collagen type I of an integrin $\alpha_{2} \beta_{1}$-binding site containing an essential GER sequence. J Biol Chem 273: 33287-33294 (1998)

2. Depraetere H, Wille C, Gansemans Y, Stanssens P, Lauwereys M, Baruch D, De Reys S, Deckmyn H. The integrin $\alpha_{2} \beta_{1}$ (GPIa/IIa)-I-domain inhibits platelet-collagen interaction. Thromb Haemost 77: 981-985 (1997)

3. Isono K, Asahi K, Suzuki S. Studies on polyoxins, antifungal antibiotics. XIII. J Am Chem Soc 91: 7490-7505 (1969)

4. Isono K, Sato T, Hirakawa K, Funayama S, Suzuki S. Biosynthesis of the nucleoside skeleton of polyoxins. J Am Chem Soc 100: 3937-3939 (1978)

5. Waddleton D, Ramachandran C, Wang Q. Development of a time-resolved fluorescent assay for measuring tyrosinephosphorylated proteins in cells. Anal Biochem 309: 150-157 (2002) 